\title{
Research Paper: The Effect of a 4-Week Suspension Train- ing With Total Resistance Exercises on Performance and Balance in Healthy Children
}

\author{
Majid Barzegari' ${ }^{1}$ (D) , Sadredin Shojaedin ${ }^{1 *}$, Zahra Karimi²
}

1. Department of Sport Pathology and Corrective Movements, School of Physical Education and Sport Sciences, Kharazmi University, Tehran, Iran. 2. Department of Pathology and Corrective Movements, South Tehran Azad University Branch, Tehran, Iran.

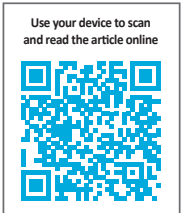

Citation Barzegari M, Shojaedin S, Karimi Z. The Effect of a 4-Week Suspension Training With Total Resistance Exercises on Performance and Balance in Healthy Children. Physical Treatments. 2019; 9(4):235-242. http://dx.doi.org/10.32598/ptj.9.4.235

http://dx.doi.org/10.32598/ptj.9.4.235

(c) (i) (8)

Article info:

Received: 10 Feb 2019

Accepted: 12 Aug 2019

Available Online: 01 Oct 2019

Keywords:

Suspension training, Total Resistance Exercises (TRX), Balance,

Performance

\section{A B S T RA C T}

Purpose: The present study investigated the effect of a 4-week training with Total Resistance Exercises (TRX) on performance and balance in healthy children.

Methods: In total, 26 children aged 12-16 years were purposefully selected. Then, the study subjects were randomly divided into two groups of TRX $(n=13)$ and control $(n=13)$. The static and dynamic balance and performance were measured by Sharpened Romberg Test, Y Balance Test, and Functional Movement Screen (FMS), respectively. The experimental group performed TRX for 4 weeks; three 55-minute sessions per week. The obtained data were analyzed using statistical tests, including t-test and Analysis of Covariance (ANCOVA) in SPSS.

Results: The t-test results suggested a significant difference between the pretest-posttest scores of all variables assessed in the experimental group $(\mathrm{P} \leq 0.05)$. In addition, ANCOVA results indicated that performing TRX significantly improved the balance and FMS score in the experimental group, compared to the controls $(\mathrm{P} \leq 0.05)$.

Conclusion: Conducting 4 weeks of TRX training significantly improved static and dynamic balance and FMS values in healthy children; therefore, coaches can use these exercises to improve balance and performance and prevent injury in this group.

\footnotetext{
* Corresponding Author:

Sadredin Shojaedin, PhD.

Address: Department of Sport Pathology and Corrective Movements, School of Physical Education and Sport Sciences, Kharazmi University, Tehran, Iran. Phone: +98 (21) 66249011

E-mail: shojaeddin@khu.ac.ir
} 


\section{Highlights}

- TRX training improved static and dynamic balance in healthy children.

- TRX training improved FMS in healthy children.

- Coaches can use TRX to improve balance and performance and prevent injury in heathy children.

\section{Plain Language Summary}

The TRX suspension training improved static and dynamic balance and functional movement patterns in studied children. Sports coaches and teachers can use these exercises in sports curriculum or bodybuilding exercises to improve children's balance and performance. Future studies could examine the impact of TRX suspension training on different age groups. Such data could help to prevent injury in athletes of different sports.

\section{Introduction}

ports science has recently been developed. In addition to focusing on fitness and general health, it has found particular applications. Coaches use physiology, nutrition, biomechanics, psychology, and exercise science to prepare athletes for sports competitions. Moreover, they continuously seek to improve athletes' performance from childhood to adolescence. The nervous system matures earlier in childhood; therefore, most neural adaptations and neuromuscular coordination occur in this life period. Childhood is a vital period to increase motor skills in different sports. The development of the nervous and motor systems (muscles and bones) are interconnected; as the nervous system's interaction with the motor systems increases, more complex movements are formed and targeted [1]. Therefore, athlete children require exercises that provide higher neural adaptations, in addition to increasing physical fitness. Resistance exercises were previously assumed to harm children and adolescents; however, recent reports knowledge suggested that these exercises can be performed safely.

Moreover, they indicated that if performed correctly, it can reduce injury risk in sports activities and competitions. Resistance training in children and adolescents improves body composition as well as bone mineral density and has no negative impact on the puberty process [2]. Therefore, children require some resistance training that utilizes body weight. Furthermore, it should be safe and enjoyable and have the most significant impact on their nervous system. Cook et al. Have introduced Functional Movement Screen (FMS) concerning pre-season screening and performance-related factors. The FMS consists of 7 movement tests, i.e., capable of identifying the limitations and changes of standard movement patterns These tests were designed to interact between kinetic chains and the stability required to perform fundamental movement patterns. The FMS can be performed in 5-10 minutes; therefore, it can be easily used by coaches for pre-season assessments.

Studies that have investigated the relationship between FMS results and injury occurrence predicted the FMS score and injury occurrence [3, 4]. A major risk factor for the lower extremity injury is impaired balance and postural control; it is the most critical ability of athletes. Therefore, it is a determining factor in evaluating athletes' performance [5]. Thus, improving postural control and balance in the lower extremity joints as well as athletes' performance is necessary.

A functional tool recently used by the population engaged in sports and exercises is the Total Resistance Exercise (TRX) system. It is a new workout type that can be used to perform hundreds of different exercises by applying gravity or bodyweight, applying two rope-like levers for different purposes. In this training, the extent of challenge and force applied to the exercises can be manipulated by moving and changing the body posture [6]. Unlike other training, in TRX, during the upper and lower extremity movements, the core stabilizing muscles can be strongly activated by altering body posture [7]. Few studies have explored the effects of these exercises on adults; no study has investigated children and adolescents in this area. Studies on resistance training for children have concluded that before performing any training with external load, children must first be able to learn the proper technique of bodyweight movements. 
Therefore, suspension training is an optimal exercise for this purpose.

Furthermore, these exercises could help children adapt better by activating the nervous system. In addition, these exercises are performed using bodyweight with relying on bands; therefore, they seem appropriate and safe for children. However, no studies have examined the effects of these exercises on children's balance and performance. Thus, this study examined the effect of a 4-week suspension training using TRX on functional movement patterns and balance in healthy children.

\section{Materials and Methods}

This was a quasi-experimental study with a pretestposttest and control group design. Study population consisted of 26 children from all sport disciplines who voluntarily participated in the study using convenience sampling technique. To determine the sample size, the following equation was used, where $\alpha=$ significance level, $\beta=$ test power, $\mathrm{M} 1=$ mean posttest time for static balance in the control group according to the previous studies; and $\mathrm{M} 2=$ mean posttest time for static balance in the intervention group according to the previous studies.

$$
n=\left(Z_{1} \alpha / 2+\left(Z_{1}-\beta\right)^{2}\left(s_{1}^{2}+s_{2}^{2}\right) /(M 1-M 2)^{2}\right.
$$

Considering similar studies, with $95 \%$ confidence interval and $80 \%$ test power, the sample size $(\mathrm{N})$ was calculated as 12. Considering sample dropouts, the sample size was determined equal to 13 for each group. The inclusion criteria were being male, aged 12-16 years, and having general health. The exclusion criteria were a history of musculoskeletal injury or malformation, motion restriction in the lower limb joints, weakness in lower limb muscles, balance and vestibular system problems, and cancer, diabetes, or cardiovascular diseases [8, 9].

The study subjects were divided into TRX $(n=13)$ and control $(n=13)$ groups. Then, the necessary explanations of the research procedure were provided to them. Next, their parents signed an informed consent form. Consequently, they went under balance and FMS tests. For measuring the static balance of children, the Sharpened Romberg Test was used. The reliability of this test for measuring balance with eyes open and closed has been reported as 0.91 and 0.77 , respectively [10]. To perform this test, the subject stands with bare feet on a flat surface with the dominant foot in front of the non-dominant foot (heel-to-toe position).
Moreover, the subject crosses his/her arms over his/her chest with hand lied on the opposite shoulder. The subject maintains this state for 60 seconds with eyes closed. If any of the following errors occur during the test, a negative score is recorded for the subject: excessive swinging, balance loss, opening eyes, and moving hands. Each subject performed the test 3 times with a 1-minute rest between each repetition [10].

For measuring the dynamic balance of children, Y Balance Test (YBT) [11] was used. In this test, the subject stands on one foot (dominant foot) at the center of the test area (three tapes attached to the ground with zero marks located in the center; one of them was towards the anterior direction and the others were positioned 135 from other tapes) pushing to reach the three directions (anterior, posteromedial, and posterolateral), while trying to maintain balance. When reached the maximum distance, the subject has to slowly touch the measuring tape with the reaching foot and return to the initial position. Then, the reached distance (normalized by dividing by the subject's leg length; then multiplied by 100) was measured and considered as the performance rate. Like the static balance test, YBT was performed 3 times and its average value was considered as the final score. Hertel reported high reliability of 0.8-0.95 for the YBT [11].

FMS test was also used to evaluate functional movement patterns. This test includes deep squat, hurdle step, lunge, shoulder mobility, active straight leg raise, trunk stability push up, and rotary stability. Three points are allocated to correctly-performed movements without compensatory movements; in case of using compensatory movement, 2 points are dedicated; if the subject was unable to perform the movements without compensatory movements, 1 point was allocated; and he/she felt pain during a movement, no point would be considered [12]. The maximum obtainable score of this test is 21 ; scores $<14$ indicate that the subject is prone to injury [7]. The validity of the FMS test has been investigated in several studies by factor analysis method [13]. The total score of FMS test is used as an indicator of predisposition to injury, this test has an underlying factor; thus, its total score must be validated by measuring this factor, i.e., the functional movement. A number of studies with trained and untrained examiners have suggested that the FMS test has an acceptable intra-rated reliability [14].

After the pretest measurements, the test group performed a 4-week TRX suspension training for 3 sessions per week. The control group was requested to only perform their daily routine activities without any specific exercises. Prior to the intervention, a training session was held to familiarize the 
Table 1. The protocol of suspension training program using TRX

\begin{tabular}{lcc}
\hline Week & Exercise & Set $\times$ Repeating \\
\hline & Squat & $3 \times 10$ \\
& Chest press & $3 \times 10$ \\
& Forward lunge & $3 \times 10$ \\
& Low row 2 & $3 \times 10$ \\
& Plank (elbow) & 3 sec \\
& Kneeling roll out & $3 \times 10$ \\
& Lateral lunge & $3 \times 10$ \\
& Triceps press & $3 \times 10$ \\
& Single-leg squat & $3 \times 10$ \\
& Overhead extension & $3 \times 10$ \\
& Hip press & $3 \times 10$ \\
& Hamstring curl & 3 sec \\
\hline
\end{tabular}

test group with TRX training. The intervention program included a 10-min warm-up with stretching movements and a45-min TRX (Appendix 1). TRX included lower and central body exercises (Table 1). The volume and intensity of exercises were matched according to the FITT principle ( $\mathrm{F}=$ Frequency, $\mathrm{I}=$ Intensity, $\mathrm{T}=$ =Time, $\mathrm{T}=$ Type) and approved by a specialist, accordingly. Besides, all measurements were conducted in Shahid Baba Safarali high-school and all exercises in Pasargad Fitness Club located in Robat Karim County, Tehran, Iran.

For analyzing the collected data, their normality was first evaluated using the Kolmogorov-Smirnov test. The statistics of frequency, mean, and standard deviation were used for describing data; while Paired Samples ttest and Analysis of Covariance (ANCOVA) were employed for within-group and between-group comparisons, respectively. All analyses were performed in SPSS at the significance level of $\mathrm{P}<0.05$.

\section{Results}

Table 2 presents the demographic characteristics of the study participants. The ANCOVA results revealed no significant difference between the demographic characteristics of the study groups. The Kolmogorov-Smirnov test results reported that the data distribution was normal. Therefore, we used a parametric test for analyzing data.
According to the Paired Samples t-test results, there was no significant difference between the pretest and posttest mean scores of static balance, dynamic balance, and FMS scores in the control group; however, they significantly increased in the TRX group $(\mathrm{P}<0.05)$ (Table 3). The ANCOVA results indicated that after controlling the pretest effect (covariate), there was a significant difference between the two groups in the posttest phase for all three variables $(\mathrm{P}<0.05)$ (Table 4)

\section{Discussion}

The present study investigated the effect of a 4-week TRX suspension training on static balance, dynamic balance, and functional movement patterns of healthy children. The study results suggested that TRX training can improve balance and function in healthy children. More precisely, the static balance duration using the Sharpened Romberg Test, and the scores of the dynamic balance using the YBT and FMS test significantly increased after the intervention in the control and TRX groups, compared to their pretest scores.

Only one study has been conducted on the impact of TREX training on adolescents [15]. Therefore, comparing the current study results with those of other studies that used other interventions and training methods could be challenging. The present study findings are consistent with those of some previous studies; they indicated the 
Table 2. Demographic characteristics of study participants and Independent Samples t-test results

\begin{tabular}{|c|c|c|c|}
\hline \multirow{2}{*}{ Variables } & \multicolumn{2}{|c|}{ Mean $\pm S D$} & \multirow{2}{*}{$\mathbf{P}$} \\
\hline & Control group $(n=13)$ & TRX group ( $n=13$ ) & \\
\hline Weight (kg) & $62.03 \pm 6$ & $64 \pm 17.5$ & 0.31 \\
\hline Height (cm) & $165.62 \pm 4$ & $166 \pm 27.3$ & 0.18 \\
\hline $\mathrm{BMI}\left(\mathrm{kg} / \mathrm{m}^{2}\right)$ & 22.79 & 27.23 & 0.94 \\
\hline Age (y) & $14.04 \pm 4$ & $19.5 \pm 6.15$ & 0.83 \\
\hline
\end{tabular}

PHYSICAL TREA IMENTS

Table 3. Paired t-test results of the within-group comparison

\begin{tabular}{ccccc}
\hline Variables & Group & Phase & Mean Difference & P \\
\hline \multirow{2}{*}{ Static balance $(\mathrm{Sec})$} & Control & Pretest-posttest & 2.47 & 0.46 \\
& TRX & Pretest-posttest & 7.31 & 0.02 \\
Dynamic balance $(\mathrm{cm})$ & Control & Pretest-posttest & 2.15 & 0.08 \\
& TRX & Pretest-posttest & 9.01 & 0.02 \\
FMS (total score) & Control & Pretest-posttest & 0.13 & 0.26 \\
& TRX & Pretest-posttest & 3.16 & 0.003 \\
\hline
\end{tabular}

PHYSICAL TREA MENTS

Table 4. ANCOVA results of the between-group comparison

\begin{tabular}{|c|c|c|c|c|c|c|}
\hline Variables & Group & Mean $\pm S D$ & $\mathbf{F}$ & df & $\mathbf{P}$ & Eta Squared \\
\hline \multirow{2}{*}{ Static balance } & Control & $31 \pm 2.05$ & \multirow{2}{*}{73.25} & \multirow[b]{2}{*}{1} & \multirow{2}{*}{0.001} & \multirow{2}{*}{0.49} \\
\hline & TRX & $36 \pm 2.63$ & & & & \\
\hline \multirow{2}{*}{ Dynamic balance } & Control & $228 \pm 1.91$ & \multirow{2}{*}{36.21} & \multirow{2}{*}{1} & \multirow{2}{*}{0.001} & \multirow{2}{*}{0.85} \\
\hline & TRX & & & & & \\
\hline \multirow{2}{*}{ FMS score } & Control & $14 \pm 2.61$ & \multirow{2}{*}{69.26} & \multirow{2}{*}{1} & \multirow{2}{*}{0.001} & \multirow{2}{*}{0.69} \\
\hline & TRX & $15 \pm 2.04$ & & & & \\
\hline
\end{tabular}

PHYSICAL TREA M MENTS

effect of other training methods on adolescent balance. For example, Siegel et al. [16] investigated the effects of upper body resistance training, including exercises using body weights, such as pull-ups, balls, and tubes on high-school adolescents. They reported increased muscle strength and flexibility in the resistance training group [16]. Another study explored the effect of neuromuscular exercises on high-school students function. It was concluded that they had significant improvement in pull-ups, sit-ups, long jumps, and single-leg jump; therefore, these exercises could be appropriate for this group.

Mitchell et al. [17] investigated 77 children aged 8-11 years and reported a cut-off score of 14.9 for FMS in them. Although the cut-off score was not obtained in the present study, the total score of FMS test increased, compared to its pretest scores. Hübscher et al. [18] in a systematic review of neuromuscular training concluded that these exercises improve neuromuscular communi- cation and may increase balance by reducing delay in proprioceptive function. Therefore, the balance exercises designed in this study may improve balance by increasing the efficiency of sensory receptors and neuromuscular facilitation while improving the proprioceptive sense.

A significant feature of suspension training is the proper activation of the core stabilizing muscles in most movements performed by TRX [19]. In addition, there was a direct relationship between the function of core stabilizing muscles and the ability to maintain balance [20]. Training performed using TRX could strengthen the muscles that move our body parts as well as the core stabilizing muscles during a functional activity [19].

Numerous studies have suggested that association of some factors, such as core stability and core muscle strength with the lower limb alignment during functional movements [21, 22]. Willson et al. [21] assessed the re- 
lationship between core strength and lower extremity alignment during single leg squats in both genders. By determining the peak isometric torque of trunk flexion, extension, and lateral flexion, hip abduction, and external rotation, and knee flexion and extension, they found that females demonstrate risky movement patterns; this could be due to the lower isometric torque of the trunk, hip, and knee. Moreover, hip external rotation strength had the highest association with these patterns. Various studies have suggested that the strength and endurance of the core muscles increase following core stability exercises. Although overlooked in the present study, it was probably one of the reasons for the improved FMS and balance scores after TRX training, increased strength in the core stabilizing muscles and lower extremities, as well as improved neuromuscular control. The study limitations included problems with coordinating with the parents of children and their commute to a fitness club for training.

\section{Conclusion}

The TRX suspension training improved static and dynamic balance and functional movement patterns in studied children. Sports coaches and teachers can use these exercises in sports curriculum or bodybuilding exercises to improve children's balance and performance. Future studies could examine the impact of TRX suspension training on different age groups. Such data could help to prevent injury in athletes of different disciplines.

\section{Ethical Considerations}

\section{Compliance with ethical guidelines}

This study was confirmed by ethic committee of Kharazmi University.

\section{Funding}

This research did not receive any specific grant from funding agencies in the public, commercial, or not-forprofit sectors.

\section{Authors' contributions}

All authors contributed in designing, running, and writing all parts of the research.

\section{Conflict of interest}

The authors declared no conflict of interest.

\section{Acknowledgments}

This study was a research plan approved by the Faculty of Physical Education and Sports Sciences of Kharazmi University. The authors would like to thank the management of Shahid Baba Safarali High-School and Pasargad Fitness Club and all those who participated in this study for their valuable cooperation.

\section{References}

[1] Lloyd RS, Faigenbaum AD, Stone MH, Oliver JL, Jeffreys I, Moody JA, et al. Position statement on youth resistance training: The 2014 international consensus. British Journal of Sports Medicine. 2014; 48(7):498-505. [DOI:10.1136/bjsports-2013-092952] [PMID]

[2] Kraemer WJ, Ratamess NA. Fundamentals of resistance training: Progression and exercise prescription. Medicine \& Science in Sports \& Exercise. 2004; 36(4):674-88. [DOI:10.1249/01. MSS.0000121945.36635.61]

[3] Sorenson EA. Functional movement screen as a predictor of injury in high school basketball athletes [PhD dissertation]. Eugene, Oregon: University of Oregon; 2009.

[4] Kiesel K, Plisky PJ, Voight ML. Can serious injury in professional football be predicted by a preseason functional movement screen? North American Journal of Sports Physical Therapy (NAJSPT). 2007; 2(3):147-58. [PMID] [PMCID]

[5] Pashabadi AFA, Jamshidi A A, Shahbazi M. [Effect of attentional focus on postural sways and muscular activity in athletes (Persian)]. Journal of Modern Rehabilitation. 2014; 8(1):28-34.

[6] Kosmata A. Functional exercise training with the TRX suspension trainer in a dysfunctional, elderly population [MSc thesis]. Boone, North Carolina: Appalachian State University; 2014.

[7] Janot J, Heltne T, Welles C, Riedl J, Anderson H, Howard A, et al. Effects of TRX versus traditional resistance training programs on measures of muscular performance in adults. Journal of Fitness Research. 2013; 2(2):23-38.

[8] Farsi A, Ashayeri H, Mohammadzadeh S. [The effect of six weeks balance training program on kinematic of walking in women elderly people (Persian)]. Salmand: Iranian Journal of Ageing. 2015; 9(4):278-87.

[9] Kashefi M, Hemayat talab R, Pour Azar M, Dehestani Ardakani M. [The effect of two kinds of aerobic exercise on the static and dynamic balance of old men (Persian)]. Salmand: Iranian Journal of Ageing. 2014; 9(2):134-41.

[10] Fathi Rezaei Z, Aslankhani MA, Farsi AR, Abdoli B, Zamani Sani SH. A comparison of three functional tests of balance in identifying fallers from non-fallers in elderly people. Knowledge and Health. 2010; 4(4):21-6.

[11] Pollock KM. The Star Excursion Balance Test as a predictor of lower extremity injury in high school football players [MSc thesis]. Toledo, Ohio: University of Toledo; 2010. 
[12] Cook G. Movement: Functional movement systems: Screening, assessment, corrective strategies, $1^{\text {st }}$ edition. Mumbai, Maharashtra: Target Publications; 2010.

[13] Gnacinski SL, Cornell DJ, Meyer BB, Arvinen-Barrow M, Earl-Boehm JE. Functional movement screen factorial validity and measurement invariance across sex among collegiate student-athletes. Journal of Strength \& Conditioning Research. 2016; 30(12):3388-95. [DOI:10.1519/ JSC.0000000000001448] [PMID]

[14] Gribble PA, Brigle J, Pietrosimone BG, Pfile KR, Webster KA. Intrarater reliability of the functional movement screen. Journal of Strength \& Conditioning Research. 2013; 27(4):978-81. [DOI:10.1519/JSC.0b013e31825c32a8] [PMID]

[15] St Laurent CW, Masteller B, Sirard J. Effect of a suspensiontrainer-based movement program on measures of fitness and functional movement in children: A pilot study. Pediatric Exercise Science. 2018; 30(3):364-75. [DOI:10.1123/ pes.2016-0278] [PMID]

[16] Siegel JA, Camaione DN, Manfredi TG. The effects of upper body resistance training on prepubescent children. Pediatric Exercise Science. 1989; 1(2):145-54. [DOI:10.1123/pes.1.2.145]

[17] Mitchell UH, Johnson AW, Adamson B. Relationship between functional movement screen scores, core strength, posture, and body mass index in school children in Moldova. Journal of Strength \& Conditioning Research. 2015; 29(5):1172-9. [DOI:10.1519/JSC.0000000000000722] [PMID]

[18] Hübscher M, Zech A, Pfeifer K, Hänsel F, Vogt L, Banzer W. Neuromuscular training for sports injury prevention: A systematic review. Medicine and Science in Sports and Exercise. 2010 42(3):413-21. [DOI:10.1249/MSS.0b013e3181b88d37] [PMID]

[19] Kim JH, Kim YE, Bae SH, Kim KY. The effect of the neurac sling exercise on postural balance adjustment and muscular response patterns in chronic low back pain patients. Journal of Physical Therapy Science. 2013; 25(8):1015-9. [DOI:10.1589/jpts.25.1015] [PMID] [PMCID]

[20] Babakhani F, Oladghobadi K, Fatahi F. [Effect of hip abductor muscle fatigue on static and dynamic balance in elderly women (Persian)]. Salmand: Iranian Journal of Ageing. 2016; 11(2):322-9. [DOI:10.21859/sija-1102322]

[21] Willson JD, Ireland ML, Davis I. Core strength and lower extremity alignment during single leg squats. Medicine \& Science in Sports \& Exercise. 2006; 38(5):945-52. [DOI:10.1249/01.mss.0000218140.05074.fa] [PMID]

[22] Sadeghi H, Shariat A, Asadmanesh E, Mosavat M. The effects of core stability exercise on the dynamic balance of volleyball players. International Journal of Applied Exercise Physiology. 2013; 2(2):1-10. 
This Page Intentionally Left Blank 